\title{
The Role of Culture Heritage in Commercial Development and Tourism*
}

\author{
Sandro Danesi ${ }^{* *}$
}

\begin{abstract}
Territories endowed with cultural heritage, traditions, knowledge, talent, production activities, as well as activities involving services to individuals and business services, can boast benefits that can be enhanced and promoted in global markets also through appropriate communication. Territorial promotion strategies based on cultural heritage should focus on emotional aspects as well as lived experience. The social capital of the territory can be deemed as having both a positive and proactive approach towards the tourism industry.
\end{abstract}

Keywords: Cultural Heritage; Global Tourism; Global Markets; UNESCO; Tourism Promotion; Tourism Development

\section{The Role of Culture in Tourism}

The historic Italian approach to the role of culture and its consequences on tourism as a factor in social-economic development is a mirror image of the cultural and social conditions of the country itself today. How can we value and promote our cultural heritage, so widely spread across the national territory, when it is hampered by a weak civic community that is sparse in the many cities, towns, and districts on the territory?

We are talking about a community which has the ability to appreciate the wonderful culture we see before us every day from the windows of our houses but unfortunately with little knowledge of the excellent quality and therefore the strategic importance of the cultural heritage (especially that which is less wellknown), and consequently, the role played by illustrious personalities of the past, authors and creators of works of art (which were fundamental to the growth, development and renaissance of the culture in the past).

The Italian landscape and its favourable geographic location in the centre of the Mediterranean with all the benefits derived from the climate and the environment which has been constructed and shaped by the people, has resulted today in a land that is well known and appreciated all over the world. The territories present important culture, both tangible and intangible, which synthesises the genius, intuition and notable efforts undertaken by the foregoing illustrious personalities

\footnotetext{
* Invited article

** Policy Advisor and Business Consultant, Local Economy Laboratory, Università Cattolica del Sacro Cuore (info@sandrodanesi.com)
} 
who lived here, as well as those who, owing to their skills and capabilities, contributed, directly and indirectly, to this masterpiece that is in constant evolution

Thus, a change in the development administrative culture, founded on a new awareness on the part of the Public Administration as to its own roles and responsibilities, is deemed somewhat urgent, and as such may constitute a reasonable prerequisite for a change in the action logic pursued by public administration and private operators alike. The desired change should focus on increasing and promoting the participation of a number of private entities, while guaranteeing, above all, the public interest with the aim of passing from a logic of expenditure - where everything is brought forth and evaluated based solely on the available economic resources - to a project-based approach to incorporate both public financial resources and private resources with a view to enhancing local resources.

A change in the direction of modern cultural administration is becoming a matter of urgency also in the light of the current social malaise faced by different segments of population within certain territorial and urban contexts. The Polish sociologist Zygmunt Baumann, in the course of his studies, introduced and promoted the concept of "glocalization" and asserts in such respect that the fundamentals of development of any civil society - regardless of the historical period - lie in the ability of each local community to strengthen its identity by interacting with other communities at a worldwide level. Local entities, including those of modest size and small and medium enterprises, should neither overlook their own role in developing the economy of many Italian historic centres (including those that are less known in the global tourism scenario) nor the role played by small manufacturing enterprises that are capable of producing innovative components and passing down know-how in production processes, applicable at both a local and international level based on their artisan tradition.

It is therefore crucial to focus our attention on the potential of such territories and enterprises in a global market, or as Baumann suggests, in a "glocalized" setting, given the wide availability of digital communication systems (tangible and intangible), accessible by and of relevance to both an increasing number of individuals and the commodities sector, not to mention the demand of those who wish to acquire and disseminate knowledge and experiences for achieving a more fulfilling life. As of now, territories and enterprises are not in the position to interpret the strategic factors involved in development (or lack the ability to do so altogether). For this reason, their collaboration in creating development scenarios defined by various institutional units is advocated, with a view to integrate further programming modes with the aid of adequate planning and project management tools.

Understanding local culture is a benefit for many economic sectors in that it brings added value that can ensure enhanced quality and duration. Territories endowed with cultural heritage, traditions, knowledge, talent, production activities, as well as activities involving services to individuals and business services, can boast benefits that can be enhanced and promoted in global markets also through appropriate communication. Cultural heritage sites also represent a context for socialization, housing, trade and tourism and where every investment in both private and public sectors contributes to improving the other sectors aswell. 


\section{Cultural Valotisation and Tourism Development}

The U.S. economist John Kenneth Galbraith, one of the most celebrated economists of the last century, explains the miracle of post-war Italian reconstruction by underlining the vital role played by its culture. In this respect he states: "...the real reason is that Italy has incorporated into its products an essential component of culture, and cities such as Milan, Parma, Florence, Siena, Venice, Rome, Naples and Palermo display in their standard of living a huge amount of beauty". This quote leaves space for reflection on the role of cultural heritage as the driving factor in the "Made in Italy" production.

Article 9 of the Italian Constitution defines the bond between cultural heritage, landscape and knowledge, and holds the entire society accountable for the preservation of cultural heritage.

Considering the "landscape/territory as the visual manifestation of the lived experience of one or more individuals", the social capital of the territory can be deemed as having both a positive and proactive approach towards the tourism industry and connected sectors, within the boundaries of a balanced relationship with the local community.

Italy has played a vital role in the production of works of art and has a strong role still today in promoting "Made in Italy" thanks to Italian genius derived from millenary cultural traditions (in which both inhabitants and places are steeped), which contributed to the making of excellent products. We must be aware of the fact that the main cultural traits of the "Made in Italy" tradition entail preservation, promotion and management of the territories listed by UNESCO, and as such, specific measures should be implemented to endow such territories with excellent services both in terms of tradition and innovation. From this perspective, raising awareness among the stakeholders involved in defining future scenarios and identifying the necessary actions aimed at the safeguard and perseveration of territorial resources, on the one hand, and their enhancement and promotion, on the other hand, should become a central issue in the political scene.

According to UNESCO, "culture can be considered, in a broad sense, as a unique combination of spiritual, material, intellectual and emotional aspects that distinguish a society or a social group. It should embrace not only art and literature, but also human lifestyle, fundamental human rights, systems of values, traditions and beliefs".

Intangible cultural heritage transmitted both orally and by imitation from generation to generation, is constantly reinvented by communities and groups as a response to the surrounding environment and their interaction with nature and their own history. Cultural heritage gives people a sense of identity and continuity and fosters respect for cultural diversity and human creativity.

Different aspects revolve around culture and cultural heritage, some of which seemingly fall outside the scope of this paper. In the coming years, territorial authorities shall be called to improve their development policies and become more competitive with other territories around the world that are currently launching and strengthening development strategies to make their mark on the international scene.

As regards Italy, the objective is to safeguard and valorize the identities of its many territories, not just those that are well known for their excellence. An important point of strength and the ensuing opportunity consists in the many micro- 
identities at a local level that characterize the Italian territory, which, unfortunately, are mostly overlooked by the resident population.

These territories bear an inherited identity and are yet to be recognized as cultural heritage perhaps owing to the fact that they recall memories of past eras mainly characterized by poverty, not to mention many illustrious personalities who used to live or sojourn there, which more often than not failed to highlight the potential of such cultural sites of becoming a driving-force for development or the imprint of a tangible or intangible peculiarity.

If we add to that the fact that such identities are underrated (apart from worldfamous Italian cities of art) and not consistently promoted oversees, we realize that Italy has a wealth of high-quality cultural heritage, but, alas, little known.

Alongside big cities like Florence, Rome, Venice and Naples (and their relative cultural heritage) characterized by a constant flow of tourist arrivals and consequent economic impact, there are numerous towns and hamlets mostly unheard of but extremely rich in terms of cultural heritage and ancient traditions, not to mention intangible heritage such as literary works and music compositions.

Quite often however, such heritage is not recognized as added value of the place of origin and is at risk of being destroyed by commercial exploitation.

$\square$ For example, Pinocchio, the masterpiece of Italian literature of worldwide renown, is constantly transcribed and adapted into plays to meet the demand of markets that are totally unrelated to its context of origin, whereas Collodi, the hamlet where the story is set, is currently in need of recovery and restoration.

Neighbourhood commercial activities, hotels, restaurants and similar establishments, besides public events organizers, could gain significant economical benefits from such lesser - known sites. However, prior to developing tourism business strategies, such entities need to become acquainted with these places and believe in the potential of the surrounding landscape and the cultural heritage present therein.

$\square$ Another example is the degeneration of the concept of "main street" or "urban commercial strip", owing to the advent of American shopping malls around the 60s. The term "mall" literally translates as "strip, main street or pedestrian island" and the logic behind these shopping centres is the attempt to replicate an "artificial" city centre. Large malls have always played an important role at the social level, as they have become actual meeting places where people go shopping and can find a wide range of services inside a hermetically sealed environment, but are "secluded" at the same time, as such structures are relocated outside of the city centres from which they take their name.

Over the last decade, the U.S. has been considering a change of course; with the help of urban designers and citizen associations, projects and investments are being currently undertaken with an aim to revive urban city centres left empty due to the impact of large chain stores. Also in Italy, several city councils are moving in this 
direction with the construction of the so-called "natural shopping centres" that refer to an ideal of the city historic centre.

This calls for further awareness of a territory's value in terms of cultural heritage, of which Italians, more than anybody, can bear testimony since the history and tradition of such territories belong to the respective contexts.

It is crucial to recognize the value of both tangible and intangible heritage that can be promoted and commercialized at the international level through the exploitation of the available technological instruments, in order to represent and convey the entire spectrum of values associated with such heritage and attract more stakeholders and investors.

Italy boasts an extraordinary cultural heritage, both in terms of quality and quantity, and bears specific identities, some of which are concentrated in major cities of art and others in territories inappropriately defined as "minor" or "less known".

Territorial promotion strategies based on cultural heritage should focus on emotional aspects as well as lived experience, as pointed out by several tourism studies undertaken in northern European countries, in the endeavour to convey the excellence of the territory to tourists also through images, storytelling and descriptions.

A project stemming from the initiative of several Northern European communities aimed at analyzing the role of the Langobards in Italy (in particular those who had settled in the Apennines mountain zone), could be a source of inspiration for sharing a part of our cultural heritage with other peoples in the future.

On the other hand, revisiting the culture and conflicts of past eras could help us understand the importance of the solutions adopted at that time to establish peace.

The Langobards assimilated the positive elements of the local culture, e.g. its legal system, religion and architecture. Their intention was to settle in Italy for good and gradually became closely related with the local population. In particular, during the time of Countess Matilde, vice-queen of Italy and cousin of Emperor Frederick II, the Langobards achieved high levels of integration with the locals.

To improve the historical knowledge of cultural heritage, information and communication strategies aimed at the effective exploitation of such heritage at local level, could be provided even by foreign stakeholders living in Italy. In terms of investment, this could represent an opportunity to attract foreign capital; foreign investors could set up plans for rehabilitating cultural heritage in Italy involving communication, dissemination and advertising (for example Disney, as regards the village of Collodi where the Pinocchio fairy tale is set).

It would be as if they acquired a cultural asset without exchange of money. These investors would take control of the planning and dissemination of the initiative, while Italy would be left in charge of a part of the restoration works. In such a hypothetical scenario (we certainly hope it does not occur in Italy), a further form of competition may arise with the difference that the cultural and tourism destinations controlled by our competitors lie right at the heart of the Italian territory, as is currently the case with several tourism and real estate transactions. 
Notwithstanding the above, Italy would still have some opportunities for developing its own cultural heritage located in other countries. However, our nation would probably find difficulty in obtaining sufficient financial resources to make investments in other such countries.

Promoting knowledge of cultural heritage calls for a civil society that is willing, available and rich in both social and economical terms.

In such scenario, the development of the binomium composed by "cultural and manufacturing activities" could play a role in the traditional sectors present on our territory, for example, industries derived from the development of local craftsmanship and skill, typical of certain environments and reflected in many products, such as those of the fashion sector, for example.

The valorisation of a locality with its tangible and intangible identities cannot rely solely on tourism. It is important to recognise the value of the labour and cultural identities that distinguish a given locality, while striving to maintain effective linkages between tourism and various other sectors (tourism and economic development should go hand in hand) in order to satisfy the demand of local communities and improve their quality of life. It is worth pointing out that the creation of Disneyland-inspired touristic areas is a concrete risk.

The majority of artistic, cultural and landscape heritage in the world is concentrated in Italy. It is estimated that there are 97,714 cultural heritage sites, of which 9,172 are located in Tuscany; 20,000 historical centres (from Rome to the smallest village in the Apennines), of which at least 1,000 are of excellent quality, not to mention 40,000 citadels and castles, 95,000 churches (a third of which are of fundamental importance according to art history), 1,500 convents, 30,000 historic buildings with at least 4,000 gardens (not less historical than the said buildings), thousands of libraries of which 3,100 are of ecclesiastical property, and lastly, over 30,000 parish, bishop and town council archives. Within such scenario, UNESCO recognizes as Italian cultural heritage 51 tangible cultural sites and 3 intangible ones, that is: Canto a Tenore (a form of polyphonic singing developed within the pastoral culture of Sardinia), Opera dei Pupi (Sicilian puppet theatre) and the Mediterranean Diet.

The data above reflect the benefits that are exploitable by the nation as a whole. Even though such benefits cannot be considered absolute when compared to the whole world, nonetheless they are more than comparable with the benefits that very few countries can boast of. Italy can compete in the world owing to the attractiveness of its cultural resources, not only for tourism-related purposes; in this respect, we believe that increasing the attractiveness of tourism destinations in connection with social and economical development is feasible.

To this end, serious consideration should be given to the preservation, valorisation, promotion and dissemination of cultural heritage, as well as the necessary accommodation establishments. The objective is to offer a wide-ranging series of tourism and commercial services with the aim to promote knowledge of the site and enhance, at the same time, the experience of landscape as a visual manifestation of lived experiences. 
In this way, the social capital of the cultural site, which determines its essence at the various levels of civil society, is able to establish a positive and proactive relation with tourism with the view of achieving a balanced relationship between tourist numbers, residents and activities.

The fate of a territory depends on the responsibility of the local community and its ability to interact with it; in such sense, a balance is reached when the citizens themselves, via strategic planning, succeed in promoting programmes focused on the preservation of cultural heritage as well the enhancement of urban spaces and services catered to the resident population.

Therefore, it appears necessary to identify and describe the absolute and comparative values present in a given territory, as well as the criteria (more or less formal) adopted in recognizing a value (e.g. UNESCO heritage sites) and the relevant valorization and dissemination, in order to increase knowledge about an existing a site and promote it effectively to avoid settling for merely formal recognitions.

In this specific case, there are resources (e.g. the value of a book) associated with both the value of the community where the author grew up or settled and the value of the territorial elements that are characteristic of said author's birthplace or place of adoption. Such values should be embedded in the history of the individual/territory and ingrained in the collective memory of the town or towns concerned.

According to such perspective, which tends to retain and rely on the memory of events rooted in the past, efforts should be taken to valorize a given territory in virtue of the fact that it was home to the author of a famous book and witnessed both the life path the professional path of said author.

Such value is incorporated into a territory since the day a book was published for the first time, and thanks to the constant investments made by some stakeholder, that book is still remembered today.

According to the above, it is possible to qualify a value defined as "shadow" and "indirect", even though it still remains a value, and as such, cannot be easily relocated by foreign investors since it belongs to the territory and the people who have experienced it.

If, instead, an activity of an exclusively commercial nature linked to the book is undertaken without considering the territory to which the author belongs, to retain its value, the book in question would need to be promoted and commercialized in other parts of the world deemed more suitable to meet the demand of tourists or other stakeholders.

Vice versa, if we ascribe a value to both the cultural asset in question and the place where it was devised and written, steps should be taken to make the place exploitable all year round, through a form of cultural tourism integrated with the resident population's own times and activities.

In this respect, it becomes crucial to set up effective strategies aimed at the preservation and promotion of each cultural heritage site to the minimum extent necessary so as to make the same distinguishable while reviving and re-inventing it. Aristotele once stated: "to stay alive, a place must be able to regenerate itself."

The arguments above give space to an important aspect that is rather overlooked within different territorial ambits, that is, Information Communication Technology 
applied to cultural heritage and consequently to tourism, artisan and agricultural resources of the territory being promoted also at a commercial level.

Modern communication technologies help improve both the tourist experience and the conventional tourist accommodation services through targeted promotion of targeted information services and other offerings, also in connection with infrastructure. Many times, as we travel the roads of Italy, we are unaware of the cultural heritage of extraordinary importance that has characterized the Italian territory all along. A further challenge for territorial development may involve the creation of an absolute benefit at the territorial level, also with respect to the modes for delivering tourist information, both on- site and through the Internet.

The opportunities and strong points of tourism in Italy may favour the implementation of a new type of facility known as "diffuse hotels" within a tourism system and a national economic system, structured to the extent reasonably necessary, by relying on the knowledge of the numerous cultural attractions present also in lesser-known places. Awareness of the role of tourism and people's culture may prove essential in fostering such type of accommodation and could compensate for Italy's modest organisational and managerial capability. Diffuse hospitality gives value and notoriety to lesser- known places and this is what most tourists expect from a territory.

Italy is a beacon of culture, with its many cultural heritage sites in need of requalification and enhancement; however, to reach the balance point, the social capital pertaining to the tourism ambit must be able to express itself through words, consideration and acts.

Just like the industrial sector, European tourist companies (in particular Italian ones), trained for decades in the cult of quality owing to a demanding and thoughtful clientele and the excellent territories that host them, have the potential to stand out once again from among other tourist companies and destinations at a worldwide level; if properly requalified and valorized, Italian top-quality destinations can attract both Italian and foreign private investors. Conversely, small-scale private investments, regardless of their magnitude, are not sufficient to trigger a growth and development trend unless they are integrated with public investments.

Lesser-known territories in Italy endowed with recognizable excellence, capable of creating a dialogue between public and private entities as regards shared development projects (realizable within a set time) are bound to become the new touristic destinations. In fact, several territories became popular touristic destinations after being "discovered" by foreign enterprises instead of being "rediscovered" and enhanced by the locals, as in the case of the medieval village of Castelfalfi in the Municipality of Montaione, in the province of Florence. In this case, the local community took part in the decision-making process concerning investment projects aimed at heritage requalification. This doesn't mean that local communities are doing something wrong, but they need to see things with different eyes and strive to raise awareness among the locals as to values, absolute benefits and available sectors.

It is estimated that in the coming years people will travel more and more thanks to improved road infrastructure and modern communication means, mainly for tourism-related purposes and for gaining a greater understanding of other cultures. Without the need for structural investments in raw materials (as they are already 
available, i.e. culture and cultural heritage), Italy is ready to attract holidaymakers who seek to combine relaxation with knowledge, leisure, a high-quality physical environment and safety.

As a matter of fact, the instability linked to the security of citizens and tourists alike could be detrimental to the Italian tourism industry, as was the case with the North African regions whose economic development had always relied over the past years on their coastal tourist attractions and in part on their cultural offer. The detrimental effects of economic instability in Italy is already evident and can be seen in the real estate sector, involved in the attraction of residential foreign investments in tourist areas, as well as tourism and productive investment projects.

\section{Tourism and Developing Countries}

BRICS countries will likely see a slowdown in their growth in the near future; we don't know whether it will be temporary, but should this not be the case, such countries could trigger a different development trend not only due to the positive factors linked to their demography and the low cost of labour, but also to the institutional and organizational innovation that has characterized the consolidation of the society and the economy all along. As regards Europe and other developed nations, such scenario could open up new margins of growth, unexpected up till now.

As regards emerging nations, entering a lower gear would cause a decrease in their demand on world markets, while favouring price control, slowing down commercial speculation that relies on market up-trends, and increasing commercial and touristic purchases for especially notorious top-quality products. Energy provided at lower prices are beneficial for Italian and European industries that, despite suffering from the lack of raw materials, can rely on a solid industrial foundation, as they have done for decades. Such beneficial effects could extend to sectors that have always received little consideration, such as the agri-food sector, which continues to be a point of strength in Southern Europe, Italy included. Moreover, should the reasons for the economic slowdown in BRICS countries turn out to be a symptom of a deeper underlying problem triggered by the change in the western models of consumption following the global crisis, significant opportunities could open up for Europe.

Low-cost production, in which emerging countries still excel today, used to rely on work orders coming from western countries focused on saving money while maintaining the same consumption standard. However, Western consumers are no longer orientated towards buying low-cost products in large quantities, but rather, quality at a reasonable price and higher-priced products, provided they are of recognized excellence. However, emerging countries are not yet ready to offer such quality despite the innovation and technology transfer from western countries, given their inability to convey the same "pathos" associated with Italian products.

In such respect, lesser-known territories have the same development potential as top-quality small and medium Italian enterprises, despite being little-known. Development opportunities may arise for those territories that are able to devise appropriate promotional strategies and appealing tourist experience products that 
can stand comparison with the tourist experience offered by well-known, topquality tourist destinations.

In such scenario, well-known destinations shall need to implement development strategies as competitors in other similar destinations in the world, while lesserknown destinations should seek to incorporate similar elements of excellence that cannot be compared with the high content of knowledge and emotion that wellknown destinations are able to transmit. For example, a fashion brand of worldwide fame and a high-quality lesser-known brand share the same capability of conveying style, imprint and emotion. Similarly, a comparison between a well-known tourist destination and a lesser-known one shows that both share the same essential factors such as experience, emotion and detail, all factors that can be conveyed even by a lesser - known destination.

According to such approach, opportunities can open up also for lesser-known territories with beneficial effects on commercial and manufacturing activities. However, much will depend on their ability to create an atmosphere capable of conveying emotions, taste and style, although less attached to the notoriety of the site.

\section{Conclusion}

In conclusion, at the heart of the social economic development of local communities in Italy, which are forced to compete in the world economy, lies the need of the same to "wake up from their coma and regain mental alertness", or better said, gain awareness of their overall cultural heritage (not just culture but heritage in general). This may constitute the basis for a renewed development agenda. Apart from that, they must "reclaim knowledge", in particular, the knowledge ingrained in the DNA of the Italian people permeated with beauty, strength and wisdom.

Willingness, conscience, awareness, heritage and also beauty, strength and wisdom are key words that may characterize the near future and prompt us to embark on a path of innovation in terms of a renewed and qualified interest towards the values embedded in cultural, artistic, historical and environmental heritage that has no equal in the world and encompasses a richness that pertains exclusively to the Italian territory.

\section{Bibliography}

Avellino, M. S. (2016). Managing Heritage Site Interpretation for Older Adult Visitors, Symphonya.

Emerging Issues in Management (symphonya.unimib.it), 2, 93-107.

http://dx.doi.org/10.4468/2016.2.09avellino

Besculides, A., Lee, M. E., \& McCormick, P. J. (2002), Residents' perceptions of the cultural benefits of tourism, Annals of Tourism Research, 29(2), 303-319. http://dx.doi.org/10.1016/S0160-7383(01)00066-4

Briassoulis, H., Van der Straaten J., (2000), Tourism and the Environment: Regional, Economic, Cultural and Policy Issues. Springer Science \& Business Media, New York.

Brondoni, S.M., (2016), Global Tourism Management. Mass, Experience and Sensations Tourism. Symphonya. Emerging Issues in Management (symphonya.unimib.it), 1, 7-24. 
http://dx.doi.org/10.4468/2016.1.02brondoni

Chapple, K., Jackson, S. and Martin, A.J. (2010), Concentrating creativity: The planning of formal and informal arts districts, City, Culture and Society, 1, 225-234.

http://dx.doi.org/10.1016/j.ccs.2011.01.007

Codignola, F. (2016). Creativity Management: Milan as a Global Capital for Value Creation, Symphonya. Emerging Issues in Management (symphonya.unimib.it), 2, 108-124.

http://dx.doi.org/10.4468/2016.2.10codignola

Cooper, C., Fletcher, J., Fyall, A., Gilbert, D., Wanhill, S., (2008), Tourism: Principles and Practice, Pearson, Harlow.

Corti., A., (2016), Global Tourism. New Volatility, Old Statistics. Symphonya. Emerging Issues in Management (symphonya.unimib.it), 1, 25-30.

http://dx.doi.org/10.4468/2016.1.03corti

Joppe, M. (1996), Sustainable community tourism development revisited, Tourism Management, 17(7), 475-479.

http://dx.doi.org/10.1016/S0261-5177(96)00065-9

McCabe, S., Johnson, S., (2013) The Happiness Factor in Tourism: Subjective Well-being and Social Tourism. Annals of Tourism Research, 41, 42-65.

Pattanaro, G., Pistocchi, F., (2016), Linking Destinations Through Sustainable Cultural Routes. Symphonya. Emerging Issues in Management (symphonya.unimib.it ), 1, 83-96.

http://dx.doi.org/10.4468/2016.1.09pattanaro.pistocchi

Silberberg, T. (1995), Cultural tourism and business opportunities for museums and heritagesites, Tourism Management, Vol. 16, num. 5, pp. 361-165. 